\title{
Description of Echolocation Call Parameters for Urban Bats in Vietnam as a Step Towards a More Integrated Acoustic Monitoring of Urban Wildlife in Southeast Asia
}

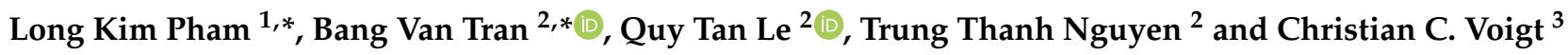 \\ 1 Department of Fisheries, School of Agriculture and Aquacuture, Tra Vinh University, Tra Vinh City 87100, Vietnam \\ 2 Southern Institute of Ecology, Vietnam Academy of Science and Technology, Ho Chi Minh City 700000, Vietnam; \\ TanQuyLe.2409@outlook.com (Q.T.L.); nguyenthanhtrung0805@gmail.com (T.T.N.) \\ 3 Leibniz Institute for Zoo and Wildlife Research, Alfred-Kowalke-Str. 17, 10315 Berlin, Germany; \\ voigt@izw-berlin.de \\ * Correspondence: kimlong_phm@tvu.edu.vn (L.K.P.); tvbang@sie.vast.vn (B.V.T.)
}

check for updates

Citation: Pham, L.K.; Tran, B.V.; Le, Q.T.; Nguyen, T.T.; Voigt, C.C. Description of Echolocation Call Parameters for Urban Bats in Vietnam as a Step Towards a More Integrated Acoustic Monitoring of Urban Wildlife in Southeast Asia. Diversity 2021, 13, 18. https://doi.org/10.3390/d130 10018

Received: 16 December 2020 Accepted: 1 January 2021 Published: 6 January 2021

Publisher's Note: MDPI stays neutral with regard to jurisdictional clai$\mathrm{ms}$ in published maps and institutional affiliations.

Copyright: (C) 2021 by the authors. Licensee MDPI, Basel, Switzerland. This article is an open access article distributed under the terms and conditions of the Creative Commons Attribution (CC BY) license (https:// creativecommons.org/licenses/by/ $4.0 /)$.

\begin{abstract}
This study is the first step towards more systematic monitoring of urban bat fauna in Vietnam and other Southeast Asian countries by collecting bat echolocation call parameters in Ho Chi Minh and Tra Vinh cities. We captured urban bats and then recorded echolocation calls after releasing in a tent. Additional bat's echolocation calls from the free-flying bats were recorded at the site where we captured bat. We used the obtained echolocation call parameters for a discriminant function analysis to test the accuracy of classifying these species based on their echolocation call parameters. Data from this pilot work revealed a low level of diversity for the studied bat assemblages. Additionally, the discriminant function analysis successfully classified bats to four bat species with an accuracy of $>87.4 \%$. On average, species assignments were correct for all calls from Taphozous melanopogon (100\% success rate), for $70 \%$ of calls from Pipistrellus javanicus, for $80.8 \%$ of calls from Myotis hasseltii and $67.3 \%$ of calls from Scotophilus kuhlii. Our study comprises the first quantitative description of echolocation call parameters for urban bats of Vietnam. The success in classifying urban bats based on their echolocation call parameters provides a promising baseline for monitoring the effect of urbanization on bat assemblages in Vietnam and potentially also other Southeast Asian countries.
\end{abstract}

Keywords: acoustic parameters; discriminant function analysis; echolocation call; Myotis hasseltii; Pipistrellus javanicus; Scotophilus kuhlii; Taphozous melanopogon; urban bat

\section{Introduction}

Vietnam is a country with a large diversity of bat species, counting about 120 species in the last comprehensive review [1]. Owing to the taxonomic description of new species previously unknown to the scientific community, the number of species observed for Vietnam has continuously increased over the past years (e.g., [2-6]). Thus far, the Vietnamese bat fauna has been mostly studied in natural habitats and protected areas [7-9]. Hence, we lack information on bat assemblages in habitats with a significant anthropogenic impact, for example, those in urban environments. In many developing countries, urban areas are expanding at unprecedented rates, exposing wildlife species to novel stressors such as high impervious surfaces, light pollution, and traffic. Some bat species appear to be particularly tolerant towards these stressors, whereas others seem sensitive [10]. This phenomenon turns bats into suitable indicator species and thus model taxa to study the impact of urbanization on wildlife species $[10,11]$. Most studies on urban bats have been conducted in so-called developed countries where urbanization is already high (e.g., [12]). However, the urban sprawl, the spatial spread of urbanization is usually highest in developing countries, from which we lack insights into how bats respond to urban stressors (but see [13]). Earlier studies showed a dramatic decline in species richness for cities in 
Southeast Asia [14]. In Vietnam, the urbanization rate has increased in recent years [15,16] and, therefore, the bat fauna of recently urbanized areas will likely be heavily affected by human actions. The lack of empirical data on species richness of urban bats limits our ability to predict how the urban sprawl may impact bat assemblages in Vietnam in the future, i.e., which species will get extirpated from urbanized areas and which species will withstand anthropogenic changes. Here, we conducted a pilot study in two typical urban environments, a medium and a large-sized city, to shed light on whether or not classifying algorithms such as discriminant function analysis can be used for acoustic monitoring and automated identification of typical urban bats in Vietnam. Automatic classification of echolocation calls could support a more systematic monitoring activity of bats to understand how Southeast Asian bats respond to urban stressors.

Monitoring bat assemblages by conventional methods such as mist netting can be challenging because some species are difficult to capture. Since all bat species, except for pteropodids, use laryngeal echolocation to orient in darkness, acoustic surveys are increasingly used to survey bats in natural and urban environments $[13,17]$. Recent studies on urban bats looked explicitly at what urban factors explained species abundance and richness in urban and suburban areas [10,18-20] and what traits of bat species constituted a pre-adaptation for a city life [21,22]. This information can then formulate appropriate conservation measures to maintain or even restore bat species richness in urban environments [23]. Acoustic identification of bat species has also helped reveal cryptic species diversity, i.e., echolocation call parameters helped differentiate between two morphologically similar species [24]. For example, differences in call structures of Miniopterus magnater and $M$. fuliginosus helped to identify the species correctly, even though their morphology is almost identical [25]. In Vietnam, bat echolocation calls also helped identify cryptic species of the genera Rhinolophus and Hipposideros [26]. Many community studies have also used echolocation call parameters to classify bat species into functional groups. The most often used statistical approach for classifying bats based on call structure has been discriminant function analyses (DFA). For example, DFA helped assign Thai bats correctly to species in $96.7 \%$ of cases [27]. Similarly, bats with frequency modulating calls (FM calls) from India were assigned correctly in about $90 \%$ of cases using DFA [28]. Lastly, DFA may also support the differentiation of morphologically similar species [25] and the description of poorly studied bat assemblages [29].

Given the relatively low number of bat species in most urban areas worldwide, we suggested that DFA could act as a powerful tool to identify bat species based on their acoustic parameters in urban environments. Here, we applied the DFA approach to describe bat assemblages in two urban ecosystems of Vietnam. Considering the low species richness in urban habitats, we expected that DFA could successfully identify bats to the species level in the majority of cases.

\section{Materials and Methods}

\subsection{Bat Captured}

We monitored bats in Ho Chi Minh City $\left(10^{\circ} 48^{\prime}\right.$ N $106^{\circ} 39^{\prime}$ E) and Tra Vinh City $\left(9^{\circ} 56^{\prime} \mathrm{N} 106^{\circ} 21^{\prime} \mathrm{E}\right)$. While Ho Chi Minh is relatively large (about 9 million inhabitants in 2019) and has a long history of urban development, including historic and new buildings that provide roosting sites for many bats, Tra Vinh is relatively small (about 1.3 million inhabitants in 2019) and has expanded and developed in recent years. As a consequence, Tra Vinh hosts more green areas than Ho Chi Minh City. We conducted our study between 2019 and 2020. We captured bats between sunset and $2200 \mathrm{~h}$ using mist-nets ( $3 \mathrm{~m}$ height and $15 \mathrm{~m}$ long with $30 \mathrm{~mm}$ mesh). Nets were set up in parking areas, in front of entries to buildings or across water bodies in both cities. They were checked at $30 \mathrm{~min}$ intervals. In Tra Vinh City, bats were captured at five sites between August 2019 and May 2020 (Table 1), and in Ho Chi Minh City at six sites between May 2020 and August 2020 (Table 1). 
Table 1. The description of sampling sites from two cities and survey effort.

\begin{tabular}{cccccccc}
\hline$\#$ & City & Latitude & Longitude & Time & \# Net & \# Night & Note \\
\hline 1 & Tra Vinh & 9.921870008 & 106.346854 & May 2020 & 1 & 2 & Indoor parking area \\
\hline 2 & Tra Vinh & 10.82854802 & 106.7282675 & May 2020 & 2 & 1 & A small pond \\
\hline 3 & Tra Vinh & 10.87740471 & 106.6799775 & $\begin{array}{c}\text { August 2019 } \\
\text { May 2020 }\end{array}$ & 2 & 4 & Grassland with some trees \\
\hline 4 & Tra Vinh & 9.922454478 & 106.3476558 & May 2020 & 1 & 1 & Under the bridge \\
\hline 5 & Tra Vinh & 9.919190397 & 106.349743 & May 2020 & 1 & 1 & Abondance house \\
\hline 6 & Ho Chi Minh & 9.923449242 & 106.3434506 & May 2020 & 1 & 1 & Old building \\
\hline 7 & Ho Chi Minh & 9.938479504 & 106.337781 & June 2020 & 2 & 1 & Near Nhieu Loc canal \\
\hline 8 & Ho Chi Minh & 10.78259474 & 106.7016182 & July 2020 & 2 & 1 & Small canal \\
\hline 10 & Ho Chi Minh & 10.79325811 & 106.6957258 & July 2020 & 2 & 1 & Small canal \\
\hline 11 & Ho Chi Minh & 10.76487179 & 106.6356857 & July 2020 & 2 & 1 & Small canal \\
\hline
\end{tabular}

Specimen collection protocols and animal operations followed the Institutional Ethical Committee of Southern Institute of Ecology, Vietnamese Academy of Science and Technology (certificate number 135/QĐ-STHMN of 09 December 2016 by Southern Institute of Ecology). Specimens were preserved in $70 \%$ ethanol and deposited in the zoological collection of the Southern Institute of Ecology as an initial specimen collection to foster future studies on bat taxonomy in this region.

\subsection{Species Identification}

Currently, we lack data on bat assemblage composition for urban ecosystems in Vietnam, yet we expected to encounter mostly generalist species. Before applying the DFA analysis based on acoustic parameters, it is necessary to know the echolocation call parameters of species. Accordingly, we first identified each captured bat based on morphological traits following a published key [1]. Measured traits included forearm length (FA; measured on a folded wing from the elbow to the outermost extremity of the wrist), head and body length (HB; from the tip of the nose to the anal opening), tail length ( $\mathrm{T}$; from the anal opening to the tip of the tail), ear length (E; from the inferior emargination to the tip of the pinna), tragus length (Tr; from the inferior emargination to the tip of the tragus), hindfoot (HF; from the tarsal joint to the outermost part of the claw of the longest finger).

\subsection{Acoustics Recording and Data Analysis}

We then recorded echolocation calls of bats that flew singly in a tent made out of mosquito net (dimensions: $2 \mathrm{~m}$ height $\times 4 \mathrm{~m}$ length $\times 2 \mathrm{~m}$ width). We acknowledge that the use of a tent could affect call parameters of flying bats. However, we considered this is the only plausible way to describe the echolocation call parameters, given the paucity of data on the echolocation call behavior of urban bats in Vietnam. Additionally, we recorded bat echolocation calls at each mist netting sites to obtain echolocation calls of free-flying animals. To avoid misidentification, we compared the spectrogram of echolocation calls from freeflying animal to those of animals flying in the confined space of the tent. Echolocation calls were recorded by a U2 microphone attached to an ultrasonic recorder (SM4-Bat, Wildlife Acoustics). The sampling frequency was set at $256 \mathrm{kHz}$ and the resolution at 16bit. We placed the device in front of the tent, about three meters away, enabling us to record calls while bats were flying in the tent. We recorded at least ten files for each animal to obtain acoustic recordings of sufficient quality for further analysis.

We only used acoustic recordings with a high signal-to-noise ratio to generate spectrograms and to measure acoustic parameters. In total, we analyzed 233 echolocation calls (Table S3) of four studied species, of which 49 of Scotophilus kuhlii, 43 of Taphozous melano- 
pogon, 50 of Pipistrellus javanicus, and 91 of Myotis hasseltii. We used Avisoft SasLab Pro (Avisoft Bioacoustics, Berlin, Germany) to generate the spectrogram of animal echolocation calls and quantify the call parameters. The spectrogram was generated by the following settings: FFT size at 1024, frame size at $100 \%$, Hann window [27]. The duration of calls was measured based on the oscillogram. To avoid a potential bias by the analyzing person, we used the function "Automatic Parameter Measurements". Additionally, by using the automatic parameter measurements function, we aimed to provide information that was automatically generated as a basis for further studies that involve, e.g., machine learning for bat identification. The acoustics parameters were chosen based on information from a previous study [27]: the frequency of maximum energy ( $\mathrm{kHz}$ ) (FMAXE), start frequency (sf), terminal frequency (tf) maximum frequency (hf), minimum frequency (lf). The frequency range or bandwidth (fr) was calculated by subtracting the maximum frequency by minimum frequency. The automated analyses by the software AVISOFT determined the max, min, and peak frequency at the onset point of the call, at the maximum energy point of the spectrogram, and the endpoint of the call (Figure S2). The maximum frequency (hf) variable is the highest frequency across the call, in this case, was the highest value out of three max frequency values that the software measures at three points. The minimum frequency (lf) is the lowest frequency of the call, and it was the lowest value of three min values calculated by the software. The start frequency (sf) and terminal frequency (tf) were selected as the peak frequency at the onset and end of each call, respectively.

As one of our goals, we tested if urban bat species could be identified correctly by echolocation call parameters only. To this end, we applied a discriminant function analysis (DFA). Before conducting the DFA, we first tested the co-linearity between acoustic parameters using the variance inflation vector (VIF). We first ran the regression model with all studied variables by using the function " $1 \mathrm{~m}$ " and then calculated the VIF value by using the function "vif" of package faraway [30]. We removed those parameters with VIF values $>10$ [31]. We used the function "lda" from the package MASS to conduct the discriminant function analysis for our data (See Table S3). We used the function "LinearDA" of package "PredPsych" with a leave-one-out cross-validation method to test the classification model due to the small sample size $[27,28]$. All the analysis was done by using RStudio 4.3 [32].

\section{Results}

\subsection{The Species Diversity and Their Acoustic Parameters}

In our study, we confirmed the presence of six bat species for Ho Chi Minh City and Tra Vinh City, belonging to the families Vespertilionidae (4 species), Emballonuridae (1 species) and Pteropodidae (1 species) (Table S1, Figure S1, morphological parameters in Table S2). The Jackknife estimator for species richness revealed the total number of bat species to equal 3.88 ( \pm 0.88 ; mean \pm one standard deviation) in Tra Vinh City and $5.71( \pm 1.21)$ in Ho Chi Minh City. The species accumulation curve (Figure S2) showed the number of captured species was below the total estimated number of species at both study sites. Species recorded for Ho Chi Minh City included Pipistrellus javanicus, Scotophilus kuhlii and Myotis hasseltii. In Tra Vinh City, we recorded Taphozous melanopogon, S. kuhlii and Cynopterus sphinx by using the mist-net during the sampling; and S. heathii from dried specimens collected by our colleagues in Tra Vinh University.

We recorded the echolocation calls from captured animals of T. melanopogon (three individuals), Myotis hasseltii (six individuals), Pipistrellus javanicus (three individuals) and S. kuhlii (three individuals). Acoustic parameters of echolocation calls are listed in Table 2 for each captured species. Acoustic parameters of $S$. healthii were not available because this species was not captured during our field campaign. 
Table 2. Acoustic parameters of recorded species, $\mathrm{d}=$ duration, FMAXE = frequency at maximum energy, $\mathrm{hf}=$ the highest frequency entire the spectrogram, if = the lowest frequency entire the spectrogram, sf = started frequency, $t f=$ terminal (end) frequency, $\mathrm{fr}=$ the bandwidth of frequency of the call, $n=$ number of call in the analysis.

\begin{tabular}{|c|c|c|c|c|c|c|c|c|c|c|}
\hline Species & Location & $\mathrm{d}(\mathrm{ms})$ & $\begin{array}{c}\text { FMAXE } \\
(\mathbf{k H z})\end{array}$ & hf $(\mathbf{k H z})$ & If (kHz) & sf $(\mathbf{k H z})$ & tf $(\mathbf{k H z})$ & fr $(\mathbf{k H z})$ & $N$ & Reference \\
\hline $\begin{array}{c}\text { Scotophilus } \\
\text { kuhlii }\end{array}$ & Vietnam & $\begin{array}{c}5.48 \\
\pm 23.8 \\
\end{array}$ & $\begin{array}{c}45.64 \\
\pm 3.32 \\
\end{array}$ & $\begin{array}{c}76.27 \\
\pm 6.56 \\
\end{array}$ & $\begin{array}{c}38.94 \\
\pm 2.40 \\
\end{array}$ & $\begin{array}{c}60.41 \\
\pm 7.21 \\
\end{array}$ & $\begin{array}{l}42.66 \\
\pm 3.18 \\
\end{array}$ & $\begin{array}{l}37.32 \\
\pm 7.06 \\
\end{array}$ & 49 & This study \\
\hline $\begin{array}{c}\text { Scotophilus } \\
\text { kuhlii }\end{array}$ & India & $\begin{array}{c}2.96 \\
\pm 0.38 \\
\end{array}$ & $\begin{array}{l}45.26 \\
\pm 0.77 \\
\end{array}$ & $\mathrm{~N} / \mathrm{a}$ & $\mathrm{N} / \mathrm{a}$ & $\begin{array}{c}56.67 \\
\pm 2.06 \\
\end{array}$ & $\begin{array}{c}43.53 \\
\pm 0.76 \\
\end{array}$ & $\begin{array}{c}13.1 \\
\pm 2.25 \\
\end{array}$ & 2 & [1] \\
\hline $\begin{array}{c}\text { Taphozous } \\
\text { melano- } \\
\text { pogon }\end{array}$ & Vietnam & $\begin{array}{c}6.45 \\
\pm 1.13 \\
\end{array}$ & $\begin{array}{l}33.07 \\
\pm 5.90 \\
\end{array}$ & $\begin{array}{l}59.10 \\
\pm 5.11\end{array}$ & $\begin{array}{c}23.19 \\
\pm 1.25 \\
\end{array}$ & $\begin{array}{l}32.70 \\
\pm 3.27 \\
\end{array}$ & $\begin{array}{l}31.09 \\
\pm 5.12 \\
\end{array}$ & $\begin{array}{c}35.91 \\
\pm 5.22 \\
\end{array}$ & 43 & This study \\
\hline $\begin{array}{c}\text { Taphozous } \\
\text { melano- } \\
\text { pogon }\end{array}$ & Thailand & $\begin{array}{c}6.02 \\
\pm 3.4\end{array}$ & $\begin{array}{c}29.71 \\
\pm 2.67\end{array}$ & $\begin{array}{c}76.15 \\
\pm 20.18\end{array}$ & $\begin{array}{l}20.37 \\
\pm 6.2\end{array}$ & $\begin{array}{c}36.6 \\
\pm 10.44 \\
\end{array}$ & $\begin{array}{l}22.58 \\
\pm 5.58\end{array}$ & $\begin{array}{c}55.78 \\
\pm 20.32\end{array}$ & 33 & [2] \\
\hline $\begin{array}{c}\text { Taphozous } \\
\text { melano- } \\
\text { pogon }\end{array}$ & Malaysia & $6-14$ & $\mathrm{~N} / \mathrm{a}$ & $\mathrm{N} / \mathrm{a}$ & $\mathrm{N} / \mathrm{a}$ & $26-30$ & $24-26$ & $\mathrm{~N} / \mathrm{a}$ & $\mathrm{N} / \mathrm{a}$ & [3] \\
\hline $\begin{array}{l}\text { Pipistrellus } \\
\text { javanicus }\end{array}$ & Vietnam & $\begin{array}{c}4.78 \\
\pm 1.06\end{array}$ & $\begin{array}{l}50.30 \\
\pm 5.09\end{array}$ & $\begin{array}{c}88.27 \\
\pm 3.50\end{array}$ & $\begin{array}{c}42.27 \\
\pm 2.66 \\
\end{array}$ & $\begin{array}{c}68.23 \\
\pm 4.05\end{array}$ & $\begin{array}{c}48.03 \\
\pm 3.61\end{array}$ & $\begin{array}{c}46.00 \\
\pm 3.48\end{array}$ & 50 & This study \\
\hline $\begin{array}{l}\text { Pipistrellus } \\
\text { javanicus }\end{array}$ & Nepal & 3.84 & 36.85 & 42 & 36.19 & & 52.81 & & & [4] \\
\hline $\begin{array}{l}\text { Myotis } \\
\text { hasseltii }\end{array}$ & Vietnam & $\begin{array}{c}3.86 \\
\pm 0.50\end{array}$ & $\begin{array}{c}50.06 \\
\pm 3.09\end{array}$ & $\begin{array}{l}84.63 \\
\pm 5.42 \\
\end{array}$ & $\begin{array}{c}38.82 \\
\pm 3.12 \\
\end{array}$ & $\begin{array}{c}67.55 \\
\pm 3.75\end{array}$ & $\begin{array}{c}47.80 \\
\pm 2.31\end{array}$ & $\begin{array}{c}45.81 \\
\pm 6.31\end{array}$ & 91 & This study \\
\hline $\begin{array}{l}\text { Myotis } \\
\text { hasseltii }\end{array}$ & Malaysia & $2.5-5.5$ & $\mathrm{~N} / \mathrm{a}$ & $\mathrm{N} / \mathrm{a}$ & $\mathrm{N} / \mathrm{a}$ & $82-104$ & $\mathrm{~N} / \mathrm{a}$ & $\mathrm{N} / \mathrm{a}$ & $\mathrm{N} / \mathrm{a}$ & [3] \\
\hline
\end{tabular}

Out of four studied species that we analyzed concerning their acoustic parameters Scotophilus kuhlii demonstrated large differences between echolocation call properties emitted by animals flying in the tent and free-flying conspecifics (Table 3). We observed significant differences in six out of seven acoustic parameters to this species, except for the lowest frequency (Table 3). In all studied species, we observed the effect of the flight environment on the duration of the call (Table 3). We did not observe a significant difference for FMAXE between calls from bats flying in the tent and free-flying conspecifics for Myotis hasseltii $(\mathrm{t}=-0.4311, p=0.67)$ and Taphozous melanopogon $(\mathrm{t}=0.55174, p=0.58)$. For other parameters, we observed various differences depending on the species.

Table 3. Statistical parameters for testing differences in acoustic parameters between bats that flying in a tent and free-flying conspecifics.

\begin{tabular}{ccccc}
\hline $\begin{array}{c}\text { Acoustic } \\
\text { Parameter }\end{array}$ & $\begin{array}{c}\text { Pipistrellus } \\
\text { javanicus }\end{array}$ & $\begin{array}{c}\text { Scotophilus } \\
\text { kuhlii }\end{array}$ & Myotis hasseltii & $\begin{array}{c}\text { Taphozous } \\
\text { melanopogon }\end{array}$ \\
\hline duration & $-7.1731(0)^{*}$ & $-7.4182(0)^{*}$ & $-9.8947(0)^{*}$ & $-3.8096(0.0)^{*}$ \\
\hline FMAXE $(\mathrm{kHz})$ & $2.691(0.01)^{*}$ & $3.6796(0.001)^{*}$ & $-0.4311(0.67)$ & $0.5517(0.58)$ \\
\hline $\mathrm{hf}(\mathrm{kHz})$ & $-1.4085(0.17)$ & $5.9849(0)^{*}$ & $1.7652(0.08)$ & $0.8711(0.39)$ \\
\hline $\mathrm{lf}(\mathrm{kHz})$ & $-1.3701(0.19)$ & $-1.9089(0.07)$ & $-7.4933(0)^{*}$ & $-8.9108(0.0)^{*}$ \\
\hline $\mathrm{sf}(\mathrm{kHz})$ & $-0.0027(0.99)$ & $3.2563(0.002)^{*}$ & $2.2077(0)^{*}$ & $-2.6367(0.01)^{*}$ \\
\hline $\mathrm{tf}(\mathrm{kHz})$ & $-0.0937(0.92)$ & $3.7237(0.001)^{*}$ & $0.7845(0.43)$ & $0.8740(0.38)$ \\
\hline $\mathrm{fr}(\mathrm{kHz})$ & $-0.4044(0.69)$ & $7.4684(0) *$ & $4.692(0) *$ & $2.3334(0.02)^{*}$ \\
\hline
\end{tabular}

* denoted the statistical significance of difference. 


\subsection{The Echolocation Call Classification by Discriminant Function Analysis}

For our final DFA, the frequency range was excluded as a factor since the VIF value was 38.15. Parameters used in the final model included duration ( $\mathrm{VIF}=2.06)$, the frequency at maximum energy $(\mathrm{VIF}=5.14)$, the highest frequency $(\mathrm{VIF}=6.79)$, the lowest frequency $(\mathrm{VIF}=6.09)$, started frequency $(\mathrm{VIF}=8.57)$, and terminal $(\mathrm{end})$ frequency $(\mathrm{VIF}=6.53)$. The accuracy of classification of all calls equaled $79.0 \%$, and the accuracy of the classification model equaled $80 \%$ based on the leave-one-out cross-validation method. Specifically, DFA correctly assigned $100 \%$ of calls to T. melanopogon (Table 3 and Figure 1 ). The DFA identified bat calls with high accuracy to M. hasseltii and P. javanicus at $80.1 \%$ and $70.0 \%$, respectively, but at lower accuracy to S. kuhlii $(67.3 \%$, Table 4). We observed some level of misidentification for calls of these species (Table 3). According to the DFA, these species also lumped as a group within the bat assemblage (Figure 1).

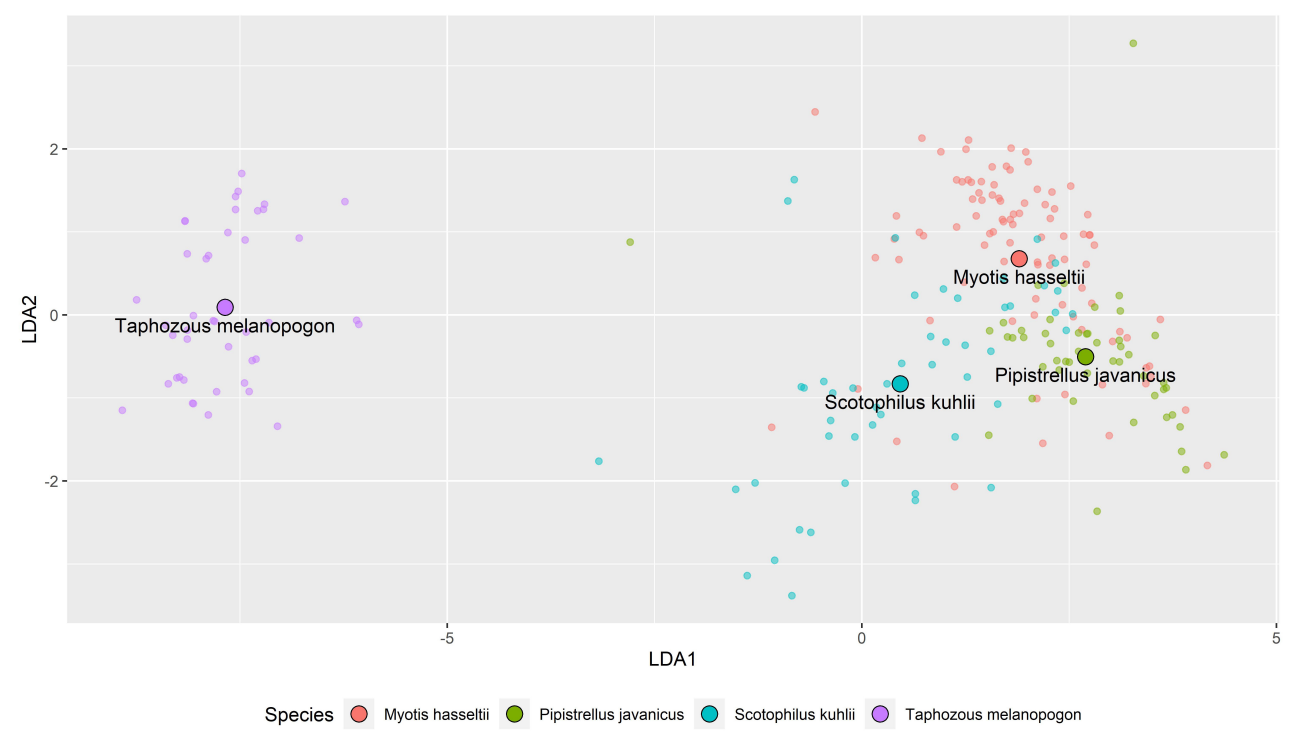

Figure 1. Plot of the linear discriminant functions LDA1 and LDA2 that separate echolocation calls of Taphozous melanopogon from those of the vespertilionid species.

Table 4. Cross-validation classification matrix for studied species.

\begin{tabular}{|c|c|c|c|c|c|}
\hline \multicolumn{6}{|c|}{ True Group } \\
\hline As predicted group & Myotis hasseltii & Pipistrellus javanicus & Scotophilus kuhlii & Taphozous melanopogon & Sum \\
\hline Myotis hasseltii & 73 & 14 & 15 & & 102 \\
\hline $\begin{array}{c}\text { Pipistrellus } \\
\text { javanicus }\end{array}$ & 13 & 35 & 1 & & 49 \\
\hline Scotophilus kuhlii & 5 & 1 & 33 & & 39 \\
\hline $\begin{array}{l}\text { Taphozous } \\
\text { melanopogon }\end{array}$ & 0 & 0 & & 43 & 43 \\
\hline Total & 91 & 50 & 49 & 43 & 233 \\
\hline n correct & 73 & 35 & 33 & 43 & 184 \\
\hline$\%$ correct & 80.80 & 70.00 & 67.34 & 100.0 & 78.96 \\
\hline
\end{tabular}

\section{Discussion}

Our capture effort revealed a low species diversity of insectivorous bat species in the urban environments of Ho Chi Minh City and Tra Vinh City. All observed species are considered generalist species since they are common in Southeast Asian cities, including those in Vietnam [1,33]. The first study in Vietnam on urban bats was conducted in Hanoi, where five bat species were reported [34]. For the larger metropolitan area of Hanoi, previous 
studies reported 13 species [1,34,35]. In Ho Chi Minh City, the largest city in Vietnam, the number of bat species was 13 species for the whole metropolitan area [1]. Three out of these 13 species were recorded for the most heavily urbanized areas in the centre, namely Taphozous melanopogon, T. theobaldi, and Scotophilus heathii [1]. This study added three more species to this list: S. kuhlii, Pipistrellus javanicus and Myotis hasseltii, making it six species for the urban ecosystem of Ho Chi Minh City. This study captured nearly $80 \%$ of all bat species previously recognized for Vietnam cities based on mist-netting effort. Therefore, future bat fauna surveys should expand to capturing bats close to roosting sites in addition to foraging grounds.

To our knowledge, the echolocation call parameters documented in our study are the first reported for the studied species in Vietnam. Some notes on the frequency ranges and peak frequencies at maximum energy for our study species can be found in work by Kruskop [1], but this source lacks many details of the echolocation calls. Myotis hasseltii was reported to produce FM calls with high intensity, particularly for frequencies around 45-50 kHz [1]. Our data is consistent with those from previous reports for the species in Vietnam. The species was recently recorded for Ha Noi City [35], but without a detailed description of the specific echolocation call parameters. Individuals reported here showed echolocation calls with a duration of about $3.86 \mathrm{~ms}$ ( $\mathrm{sd}=0.92 \mathrm{~ms}$ ), and a frequency with maximum energy at about $50.0 \pm 2.8 \mathrm{kHz}$. The pulse duration of calls emitted by this species is close to the lowest value observed before in conspecifics from Malaysia, ranging between 2.5 and $5.5 \mathrm{~ms}$ [36]. The start frequency was lower in our study than in Malaysia, with a mean frequency of $67.6 \mathrm{kHz}( \pm 3.7 \mathrm{kHz})$ compared to a range of 82 to $104 \mathrm{kHz}$ for conspecifics from Malaysia [36]. Although Pipistrellus javanicus is a common species in Vietnam and recorded in various habitats $[1,9,37]$, we are the first to describe the species' echolocation call parameters. Previous studies noted that this species has a primary echolocation call frequency with maximum energy at around 50 to $55 \mathrm{kHz}$ [1]. Our data fall within this range. The frequency parameters of echolocation reported for Vietnamese $P$. javanicus is relatively high compared to those reported for the same species in Nepal [38], except for the lowest frequency (Table 2).

We report the first echolocation call parameters for Scotophilus kuhlii in Vietnam. These call parameters are consistent with those reported before by other studies from India [28,39] and China [40]. However, the spectrogram pattern of echolocation calls from our collection is relatively different from conspecifics recorded in China, where the echolocation call consists of four harmonics [40]. The variation in echolocation call of this species was reported to vary due to differences in habitat and geographic environments [28,41,42], but the difference in shape and pattern of call spectrograms produced by Chinese specimens and those from Indian and Vietnam are documented for the first time. Spectrograms of species-specific echolocation calls were similar in two studies from India even though the recording method differed [28,39]. It is noteworthy that even when applying the same recording method, i.e., recording bat's acoustic after release, led to dissimilar spectrograms for the same species [28,40], highlighting that echolocation call parameters of this species are variable and highly context-dependent. Since the species has a wide distribution range, further studies on species acoustic and molecular identity are needed to explain this large intra-specific variation of echolocation call parameters.

Even though we confirmed Scotophilus heathii in Tra Vinh City, we did not capture live animals with our mist-nets. Therefore, the acoustic's parameter of echolocation calls could not be analyzed for this species. Previous studies noted the FMAXE for $S$. heathii equalled $30 \mathrm{kHz}$ [1], which is much lower than that of $S$. kuhlii (45.6 kHz in this study). In future, it is necessary to capture live animals this species to document the species' echolocation calls and to test for difference between these two species.

Taphozous melanopogon from our study sites emitted echolocation calls with four harmonics, similar to those reported before for this taxon [27,43]. However, the fourth harmonic was often in lower intensity, compared to the first and second harmonic. The frequency at the maximum energy occurs for the second or first harmonic, at $33.1 \pm 5.9 \mathrm{kHz}$, which was higher than those reported before at $29.7 \mathrm{kHz}$ for conspecifics from Thailand [27] and at $30.1 \mathrm{kHz}$ from conspecifics from China [43]. The start frequency of the species in 
this study was lower than those recorded for Thai conspecifics but slightly higher than those recorded for Malaysian conspecifics. On the contrary, the call's terminal frequency was higher in specimens from Vietnam compared with those from Thailand or Malaysia (Table 1).

In previous studies, discriminant function analysis classified FM calling bat species at an accuracy of 70 to $90 \%$, depending on the taxonomic group studied [27-29]. In our study, the classifying species' accuracy was 79.0\% and deemed acceptable for identifying species based on their acoustic parameters. A misidentification was reported in some studies before due to the complex echolocation calls and importantly, the overlap in species echolocation call parameters in species of the same taxonomic group and the same functional guild [27-29]. Three out of four species studied produced broadband FM calls and only Taphozous melanopogon emitted multi-harmonics calls. Therefore, the discriminant function analysis successfully distinguished the echolocation calls of Taphozous melanopogon from those of the other species (Table 4 and Figure 1). On the other hand, our dataset demonstrated the similarity of echolocation call parameters for the three vespertilionid species (Table 2). Therefore, the accuracy of assigning to species based on their acoustic parameters was low. The species with the lowest correct identification level was S. kuhlii $(67.3 \%)$, perhaps caused by the high diversity of call properties. Calls of this species were misidentified as M. hasseltii or P. javanicus. M. hasseltii and S. kuhlii were foraging at the same place and were captured simultaneously. The similarity in habitat used and the preference for similar insect prey may highlight the membership to the same foraging guild, which suggests convergent evolution of echolocation call parameters [44]. Another reason that might affects the classification accuracy was the use of flying tent to record species echolocation call. For two species with no effect of flying tent on FMAXE, the most crucial acoustic parameter in studying bat calls, species classification accuracy based on their acoustic parameters was high, $100 \%$ for T. melanopogon and 80.8 for M. hasseltii. On the other hand, the tent's confined space affects FMAXE, of the other two species. Hence the percentage of accuracy in classifying at $67.3 \%$ to $S$. kuhlii and $70.0 \%$ to P. javanicus.

\section{Conclusions}

Our study confirmed the occurrence of more than three bat species for the urban area of Ho Chi Minh City (six species) and for that of Tra Vinh city (four species). Overall, we consider the species richness to be low compared to the bat fauna in more forested sites or protected areas. We first described echolocation calls of four urban bats species in Vietnam. However, using a flying tent was perhaps not an adequate method to record and describe some bat species' echolocation calls. Our study showed a high level of accuracy in using the acoustic parameters of bats to classify species based on DFA even when recording only a few echolocation calls. Therefore, the results provide a promising first step towards monitoring bat assemblages in urban areas in Vietnam in an automated and thus more comprehensive way. However, future studies are needed to shed light on the bat assemblages in suburban and rural areas. Further, we are in need of a comprehensive bat call library that will facilitate long-term monitoring programs to examine the effect of urbanization on bat assemblages.

Supplementary Materials: The following are available online at https:/ / www.mdpi.com/1424-281 8/13/1/18/s1. Table S1. List of recorded species and some notes for specimens. Table S2. Selected morphological parameters ( $\mathrm{mm}$; mean and range) and body mass (in g) of the species described in this study. Values are given at mean (Avg), minimum-maximum (Min-max), $n$. Min-max $(n)$ indicates that the number of examined specimens for that measurement is different from other measurements-denotes data not available. Abbreviations and definitions for measurements are given in the text of method section. Table S3: The call parameters of studied species that used for the Discriminant Function Analysis. Figure S1. The lateral view of captured bat species: Pipistrellus javanicus (a); Scotophilus kuhlii (b); Myotis hasseltii (c); Taphozous melanopogon (d). Figure S2. The species accumulation curve based on sampling effort by night of sampling for survey in Tra Vinh City (a) and Ho Chi Minh City (b) shows the continuously growing of the species richness in two survey sites. Figure S3. The illustration of automatic parameter measurements by the software. The 
spectrum-base parameters that were measured including max frequency (1), peak frequency (2) and min frequency (3) at three points of start (s), maximum energy $(p)$, and end of the call (e).

Author Contributions: Conceptualization, L.K.P. and B.V.T.; Data curation, Q.T.L. and T.T.N.; Investigation, L.K.P., B.V.T., Q.T.L. and T.T.N.; Methodology, B.V.T.; Supervision, C.C.V.; Writing—original draft, L.K.P. and B.V.T.; Writing-review \& editing, C.C.V. All authors have read and agreed to the published version of the manuscript.

Funding: This research received no external funding.

Institutional Review Board Statement: The study was approved by the Institutional Review Board (or Ethics Committee) of SOUTHERN INSTITUTE OF ECOLOGY (protocol code 135/QĐ-STHMN, approval on 09 December 2016).

Informed Consent Statement: Not applicable.

Data Availability Statement: The data presented in this study are available in https://www.mdpi. com/1424-2818/13/1/18/s1.

Acknowledgments: We would like to thank the manager board of Tra Vinh University and Southern Institute of Ecology for granting permissions to conduct the study in the area of the University and the institution. Equipment used for this research was financed through the German Federal Ministry of Education and Research (BMBF) under grant number 01DP17052 in the context of the partnership between SIE and Museum für Naturkunde Berlin within the project "Innovative approaches to biodiversity discovery and characterization" (VIETBIO). Moreover, we would like to say thanks to our friends from Tra Vinh University that help us during the field survey. We thankful our friend, Herbert H. Covert, for his helping in English of the manuscript. Finally, we also express our gratitude to anonymous reviewers for their comments and advices to improve this paper.

Conflicts of Interest: The authors declare no conflict of interest.

\section{References}

1. Kruskop, S.V. Bats of Vietnam: Checklist and an Identification Manual; Joint Russian-Vietnamese Science and Technological Tropical Centre: Moscow, Russia, 2013; p. 300.

2. Thong, V.D.; Mao, X.; Csorba, G.; Bates, P.; Ruedi, M.; Van Viet, N.; Loi, D.N.; Van Nha, P.; Chachula, O.; Tuan, T.A.; et al. First Records of Myotis altarium (Chiroptera: Vespertilionidae) from India and Vietnam. Mammal. Study 2018, 43, 1-7. [CrossRef]

3. Kruskop, S.V.; Borissenko, A.V. A New Species of South-East AsianMyotis(Chiroptera: Vespertilionidae), with Comments on Vietnamese "Whiskered Bats". Acta Chiropterologica 2013, 15, 293-305. [CrossRef]

4. Soisook, P.; Karapan, S.; Satasook, C.; Thong, V.D.; Khan, F.A.A.; Maryanto, I.; Csorba, G.; Furey, N.; Aul, B.; Bates, P.J. A Review of the Murina cyclotis Complex (Chiroptera: Vespertilionidae) with Descriptions of a New Species and Subspecies. Acta Chiropterologica 2013, 15, 271-292. [CrossRef]

5. Son, N.T.; Görföl, T.; Francis, C.M.; Motokawa, M.; Estók, P.; Endo, H.; Thong, V.D.; Dang, N.X.; Oshida, T.; Csorba, G. Description of a New Species ofMyotis(Vespertilionidae) from Vietnam. Acta Chiropterologica 2013, 15, 473-483. [CrossRef]

6. Görföl, T.; Kruskop, S.V.; Tu, V.T.; Estók, P.; Son, N.T.; Csorba, G. A new genus of vespertilionid bat: The end of a long journey for Joffre's Pipistrelle (Chiroptera: Vespertilionidae). J. Mammal. 2020, 101, 331-348. [CrossRef]

7. Furey, N.M.; Mackie, I.J.; Racey, P.A. Bat diversity in Vietnamese limestone karst areas and the implications of forest degradation. Biodivers. Conserv. 2010, 19, 1821-1838. [CrossRef]

8. Thong, V.D.; Dietz, C.; Denzinger, A.; Bates, P.J.J.; Furey, N.M.; Csorba, G.; Glenn, M.E.; Hoye; Thuy, L.D.; Schnitzler, H.-U. Further Records of Murina tiensa from Vietnam with first information on its echolocation calls. Hystrix It. J. Mammalog. 2011, 22, 129-138.

9. Thong, V.D. Bats of Cat Tien national park: Diversity, echolocation and taxonomic remarks. TAP CHI SINH HOC 2016, 37, 336-343. [CrossRef]

10. Russo, D.; Ancillotto, L. Sensitivity of bats to urbanization: A review. Mamm. Biol. 2015, 80, 205-212. [CrossRef]

11. Jones, G.; Jacobs, D.S.; Kunz, T.H.; Willig, M.R.; Racey, P.A. Carpe noctem: The importance of bats as bioindicators. Endanger. Species Res. 2009, 8, 93-115. [CrossRef]

12. Voigt, C.C.; Scholl, J.M.; Bauer, J.; Teige, T.; Yovel, Y.; Kramer-Schadt, S.; Gras, P. Movement responses of common noctule bats to the illuminated urban landscape. Landsc. Ecol. 2019, 35, 189-201. [CrossRef]

13. Jung, K.; Kalko, E.K.V. Adaptability and vulnerability of high flying Neotropical aerial insectivorous bats to urbanization. Divers. Distrib. 2011, 17, 262-274. [CrossRef]

14. Lane, D.J.; Kingston, T.; Lee, B.P.-H. Dramatic decline in bat species richness in Singapore, with implications for Southeast Asia. Biol. Conserv. 2006, 131, 584-593. [CrossRef]

15. General Statistics Office. Vietnam Population and Housing Census 2009-Migration and Urbanization in Vietnam: Patterns, Trend and Differentials; Ministry of Planning and Investment: Hanoi, Vietnam, 2011; p. 140. 
16. Nong, D.H.; Fox, J.M.; Miura, T.; Saksena, S. Built-up Area Change Analysis in Hanoi Using Support Vector Machine Classification of Landsat Multi-Temporal Image Stacks and Population Data. Land 2015, 4, 1213-1231. [CrossRef]

17. MacSwiney, M.C.; Clarke, F.M.; Racey, P.A. What you see is not what you get: the role of ultrasonic detectors in increasing inventory completeness in Neotropical bat assemblages. J. Appl. Ecol. 2008, 45, 1364-1371. [CrossRef]

18. Avila-Flores, R.; Fenton, M.B. Use of spatial features by foraging insectivorous bats in a large urban landscape. J. Mammal. 2005, 86, 1193-1204. [CrossRef]

19. Straka, T.M.; Lentini, P.E.; Lumsden, L.F.; Wintle, B.A.; Van Der Ree, R. Urban bat communities are affected by wetland size, quality, and pollution levels. Ecol. Evol. 2016, 6, 4761-4774. [CrossRef] [PubMed]

20. Straka, T.; Wolf, M.; Gras, P.; Buchholz, S.; Voigt, C.C. Tree Cover Mediates the Effect of Artificial Light on Urban Bats. Front. Ecol. Evol. 2019, 7, 91. [CrossRef]

21. Jung, K.; Threlfall, C.G. Trait-dependent tolerance of bats to urbanization: A global meta-analysis. In Proceedings of the Proceedings of the Royal Society of London. Series B: Biological Sciences; The Royal Society: London, UK, 2018; Volume 285, p. 20181222.

22. Voigt, C.C.; Kingston, T. Bats in the Anthropocene: Conservation of Bats in a Changing World; Springer Science and Business Media LLC: Berlin, Germany, 2016.

23. Gallo, T.; Lehrer, E.W.; Fidino, M.; Kilgour, R.J.; Wolff, P.J.; Magle, S.B. Need for multiscale planning for conservation of urban bats. Conserv. Biol. 2018, 32, 638-647. [CrossRef]

24. Jones, G.; Vaughan, N.; Parsons, S. Acoustic identification of bats from directly sampled and time expanded recordings of vocalizations. Acta Chiropterologica 2000, 22, 155-170.

25. Wu, H.; Jiang, T.; Liu, S.; Lu, G.; Feng, J. Acoustic identification of two morphologically similar bat species, Miniopterus magnater and Miniopterus fuliginosus (Chiroptera, Miniopteridae). Mamalia 2020, 84, 201-206. [CrossRef]

26. Thong, V.D. Acoustic identification and taxonomic remarks of Hipposiderids and Rhinolophids (Chiroptera: Hipposideridae, Rhinolophidae) in Tam Dao national park, Northeastern Nietnam. TAP CHI SINH HOC 2015, 36, 487-493. [CrossRef]

27. Hughes, A.C.; Satasook, C.; Bates, P.J.J.; Soisook, P.; Sritongchuay, T.; Jones, G.; Bumrungsri, S. Using Echolocation Calls to Identify Thai Bat Species: Vespertilionidae, Emballonuridae, Nycteridae and Megadermatidae. Acta Chiropterologica 2011, 13, 447-455. [CrossRef]

28. Wordley, C.F.R.; Foui, E.K.; Mudappa, D.; Sankaran, M.; Altringham, J.D. Acoustic Identification of Bats in the Southern Western Ghats, India. Acta Chiropterologica 2014, 16, 213-222. [CrossRef]

29. Sophany, P.; Sarith, P.; Furey, N.M. Cambodian bat echolocation: A first description of assemblage call parameters and assessment of their utility for species identification. Cambod. J. Nat. History 2013, 2013, 16-26.

30. Faraway, J. Practical Regression and Anova Using R. Available online: https://cran.r-project.org/doc/contrib/Faraway-PRA.pdf (accessed on 15 August 2020).

31. Hair, J.F.; Black, W.C.; Babin, B.J.; Anderson, R.E. Multivariate Data Analysis, 7th ed.; Pearson: New York, NY, USA, $2009 ;$ p. 816.

32. RStudio Team. RStudio: Integrated Development for R; RStudio, Inc.: Boston, MA, USA, 2019; Available online: http:/ / www.rstudio. $\mathrm{com} /$ (accessed on 30 July 2020).

33. Francis, C. A Guide to the Mammals of South-East Asia; Princeton University Press: Princeton, NJ, USA, 2008 ; p. 392.

34. Tu, V.T. Final Project Report: Conservation of Bat Assemblages in Hanoi City, Vietnam (RGS 55.02.0); Institute of Ecology and Biological Resources: Hanoi, Vietnam, 2010.

35. Tu, V.T.; Arai, S.; Kikuchi, F.; Hang, C.T.; Tuan, T.A.; Csorba, G.; Görföl, T. Rediscovery of Van Hasselt's Mouse-eared Bat Myotis hasseltii (Temminck, 1840) and its first genetic data from Hanoi, northern Vietnam. J. Threat. Taxa 2019, 11, 13915-13919. [CrossRef]

36. Heller, K.G. Echolocation calls of Malaysian bats. Säugetierkunde 1989, 54, 1-8.

37. Sơn, N.T.; O'Shea, T.J.; Gore, J.A.; Csorba, G.; Tu, V.T.; Oshida, T.; Endo, H.; Motokawa, M. Bats (Mammalia: Chiroptera) of the southeastern Truong Son Mountains, Quang Ngai Province, Vietnam. J. Threat. Taxa 2016, 8, 8953-8969. [CrossRef]

38. Habitat and Acoustic Survey and an Action Plan for Bats Conservation in the Kathmandu Valley, Nepal. Available online: https:// smcrf.org/project/habitat-and-acoustic-survey-and-an-action-plan-for-bats-conservation-in-the-kathmandu-valley-nepal/ (accessed on 27 September 2020).

39. Raghuram, H.; Jain, M.; Balakrishnan, R. Species and acoustic diversity of bats in a palaeotropical wet evergreen forest in southern India. Curr. Sci. 2014, 107, 631-641.

40. Zhu, G.; Chmura, A.A.; Zhang, L. Morphology, Echolocation Calls and Diet of Scotophilus kuhlii (Chiroptera: Vespertilionidae) on Hainan Island, South China. Acta Chiropterologica 2012, 14, 175-181. [CrossRef]

41. Thomas, D.W.; Bell, G.P.; Fenton, M.B. Variation in Echolocation Call Frequencies Recorded from North American Vespertilionid Bats: A Cautionary Note. J. Mammal. 1987, 68, 842-847. [CrossRef]

42. Wund, M.A. Variation in the Echolocation Calls of Little Brown Bats (Myotis lucifugus) in Response to Different Habitats. Am. Midl. Nat. 2006, 156, 99-108. [CrossRef]

43. Wei, L.; Han, N.; Zhang, L.; Helgen, K.M.; Parsons, S.; Zhou, S.; Zhang, S. Wing morphology, echolocation calls, diet and emergence time of black-bearded tomb bats (Taphozous melanopogon, Emballonuridae) from southwest China. Acta Chiropterologica 2008, 10, 51-59. [CrossRef]

44. Schnitzler, H.-U.; Moss, C.F.; Denzinger, A. From spatial orientation to food acquisition in echolocating bats. Trends Ecol. Evol. 2003, 18, 386-394. [CrossRef] 